\title{
25 TURNING PRODUCTS INTO SERVICES AND SERVICES INTO PRODUCTS: Contradictory Implications of Information Technology in the Service Economy
}

\author{
Neil C. Ramiller \\ Portland State University \\ Portland, OR U.S.A. \\ Elizabeth Davidson \\ University of Hawaii at Manoa \\ Honolulu, HI U.S.A. \\ Erica L. Wagner \\ Cornell University \\ Ithaca, NY U.S.A. \\ Steve Sawyer \\ The Pennsylvania State University \\ University Park, PA U.S.A.
}

\section{INTRODUCTION}

Service industry sectors of modern economies are growing rapidly, in absolute size and in comparison to the manufacturing, agriculture, and other economic sectors. Implicit in the dramatic proclamations that have accompanied this worldwide shift to the service economy is a subtext about the displacement and subordination of products. The notion of displacement speaks, in a straightforward way, to the diminishing relative importance that material products play in production and consumption and, hence, in

Please use the following format when citing this chapter:

Ramiller, N. C., Davidson, E., Wagner, E. L., and Sawyer, S., 2008, in IFIP International Federation for Information Processing, Volume 267, Information Technology in the Service Economy: Challenges and Possibilities for the $21^{\text {st }}$ Century, eds. Barrett, M., Davidson, E., Middleton, C., and DeGross, J. (Boston: Springer), pp. 343-348. 
providing opportunities for employment. That information and communication technology (ICT) enabled innovation has played a crucial role in the emerging dominance of services is well known, for example, in all aspects of financial service sectors. Subordination is more interesting because it has to do with the changing and unsettled relationship between products and services and, indeed, ambiguity in the very definition of "service" itself. This subordination has taken a variety of forms:

$\rightarrow$ Producers and purveyors of products add information-intensive service dimensions in order to enhance relationships with customers and, in some cases, to generate network effects among the customers themselves (e.g., Amazon.com's online customer reviews of books and data-based book recommendations).

$\rightarrow$ Products themselves have become servicitized in the sense that a product comes with a service component that is crucial in fully constituting the product as a meaningful "solution" for the purchaser (Vandermerwe and Rada 1988). The delivery of these components is often ICT-enabled (e.g., call centers in support of consumer electronic products).

$\rightarrow$ We witness the servicitization of products in an alternative sense, where the purchaser never takes possession of the material product but rather subscribes to the service that the product provides, with the purveyor maintaining ownership of the physical asset (e.g., ASP models of computer or software use and outsourcing of certain other kinds).

This third service phenomenon is a central element in IBM's and others' emerging interest in "services science" and the proposed academic discipline of "service science, management, and engineering" (SSME) (Chesbrough and Spohrer 2006; Rust and Miu 2006; Sheehan 2006) ${ }^{1}$. As that particular discourse tries to craft accounts of the conversion of products into services, how the ownership of assets is situated appears to be an important issue. However, when we set ownership aside, we are left with the tantalizing implication that the true, extractable value of a product is only ever realized in the services that the product provides, even where the beneficiary holds title to the product. Accordingly, some researchers have gone on to argue that all economies are service economies, and that the division between services and products is not meaningful. Instead, it is the creation of value-added services that is the basis for exchange (Vargo and Lush 2004, 2008).

Formulations that portray products as amplified by, completed by, transformed into, or reconceptualized as services reflect important economic changes. However, in this panel we further argue that services are now sometimes taking on aspects of products. Accordingly, even as we witness the servicitization of products, we can also observe the productization of services. By this we refer especially to the introductions of technical artifacts into traditional service exchanges, and the implications that these new intermediaries have for the nature of service production. That is, if we consider the traditional

${ }^{1}$ For more about IBM's efforts to define, guide and advocate for SSME, see http://www. research.ibm.com/ssme/ for definitions, discussions, and links. 
conceptualization of service as a change in the service consumer's state resulting from activities of the service provider that are jointly consummated, then productization might be evident in a variety of ways, for example,

- the inclusion of tangible and intangible goods, and reliance on ICT, as part of the service;

- the substitution of artifacts or artificial agents (with service knowledge standardized and encoded) for service provider or service consumer;

- removal of the temporal connection between production and consumption of the service, and hence the interaction of provider and consumer.

A simple example is a meal at McDonalds: the service effort - a meal - is distilled, measured, and packaged into numbered value-meals and sizes. Self-service fast food is productized and successful. A more relevant example is the bundling of iTunes with the iPod. The significance of the service is realized through its productization. More broadly, the ICT consulting activity: legions of capable young programmers and smooth business analysts swarming through your organization to create the information system of your dreams (or budget) reflects service via service productization.

Simply, ICT play a - if not the - crucial role in this reciprocal transformation. The productization of services is observed in the way that various kinds of artifacts based on ICT (much of this involving the Internet) have come increasingly to occupy and even to dominate the interaction space in which customers are called upon to cocreate service exchanges. These artifacts, acting as delegates for the organizations that offer the services, have in some cases replaced traditional human service providers; in other cases, they mediate a greater proportion of the interaction between humans; and in still other cases, they make service exchanges possible that had not previously been available or, perhaps, even envisioned.

This productization (which we might also call artifactualization) of services holds forth the promise of standardization, scalability, cost reduction, and geographic reachoutcomes of obvious appeal to managers in the provider firms. The results for service recipients may be more mixed, with convenience, speed, and reliability often being positive outcomes, but inflexibility and a lack of responsiveness also being possible. In particular, the novel, complex, recondite, obdurate, or exceptional service episode can place the customer at odds with an artifact-delegate's limited response set (and the provider's inscribed interests). In these situations, service recipients may have the means, with persistence and ingenuity, to transcend design assumptions and thus to create and experience a more robust and satisfying service encounter. However, we suggest that their interactions might be more akin to the manipulation of a product and exploration of its features, than to the negotiated exchange we more typically associated with service encounters. In this sense, what we as researchers and managers have learned about standardization, scalability, and cost reduction in the design, production, and distribution of products might apply to many ICT-enabled services.

Panelists will discuss the implications of artifacts-in-services in a set of industries/ application domains, using a range of theoretical perspectives as noted in the next section. Building from these, the intent of the panel is to explore productization as the flipside of servicitization. And, in doing this, to examine the accompanying ambiguity 
in the semantics of service" (Bar 2001; Bresnehan and Greenstein 2001). Such an examination will surface interesting social, technological, and economic issues, confront both expectations and beliefs that the producers and consumers of services might encounter in developing these transformations, and challenge those who pursue research on services to conceptualize more coherently both servicitization and productization (e.g., Metka et al. 2006; Wolff 2002).

\section{THE PANEL}

Neil Ramiller will explore the mediating role of computer-based artifacts in distance education, in a context where maintaining a high level of instructor-student interaction is an expectation (in contrast, for example, to conventional computer-based training). His experience in teaching a distance-learning MBA core course in information technology will provide material for discussion. Actor-network theory will be used as the interpretive frame.

Elizabeth Davidson will examine how information technologies are being used in the delivery of healthcare services, not only to collect and distribute medical and patient information during service delivery, but as mediators in the interactions among medical professionals and with their patients, and even as substitutes for provider or patient (or both) in some interactions. She will consider how advancing technologies may challenge the institutionalized identities and legitimized roles of providers and patients, and the implications these changes may have for field-level change in healthcare.

Erica Wagner will focus on the hospitality sector, one of the largest services industries in the world, as the context for understanding the mutual shaping involved in the productization of service experiences. Using a social shaping lens, she will consider how the production of artifacts has been necessary to move toward the "self service" trend that is dominating airlines, lodging and restaurant segments. In turn, consumer responses to the productization of their service experience will be considered. Service recipients themselves are using web 2.0 technologies such as consumer-generated content sites like TripAdvisor to create delegates that have begun shaping the way hotels perform their services.

Steve Sawyer will draw from his ongoing work on the computerization of real estate to highlight two points of relevance to the artifactualization of services. Building on concepts of computerization he will use principles of economic sociology to make two points. First, he will highlight how different mobilizing rhetorics regarding the role of a service, and who participates, leads to conflicting views on who is providing which services to buyers and sellers. Second, in doing this he will contrast the social activities of real estate agent's work with the value-adding offerings of several online purveyors of real estate data.

\section{References}

Bar, F. 2001. "The Construction of Marketplace Architecture," in Tracking a Transformation: E-Commerce and the Terms of Competition in Industries, The BRIE-IGCC Economy Project Task Force on the Internet, Washington, DC: Brookings Institution Press, pp. 27-49. 
Bresnehan, T., and Greenstein, S. 2001. "The Economic Contribution of Information Technology: Towards Comparative a User Studies," Journal of Evolutionary Economics (11), pp. 95-118.

Chesbrough, H., and Spohrer, J. 2006. “A Research Manifesto for Services Science,” Communications of the ACM (49:7), pp. 35-49.

Metka, S., Jaklic, A., and Kotnik, P. 2006. "Exploiting ICT Potential in Service Firms in Transition Economies," The Service Industries Journal (26:3), pp. 287-299.

Rust, R., and Miu, C. 2006. "What Academic Research Tells Us About Service," Communications of the ACM (49:7), pp. 49-54.

Sheehan, J. 2006. "Understanding Service Sector Innovation," Communications of the ACM (49:7), pp. 42-47.

Vandermerwe, S., and Rada, J. 1988. "Servicitization of Business: Adding Value by Adding Services," European Management Journal (6:4), pp. 314-324.

Vargo, S., and Lusch, R. 2004. "Evolving to a New Dominant Logic for Marketing," Journal of Marketing (68), pp. 1-17.

Vargo, S., and Lusch, R. 2008. "Service-Dominant Logic: Continuing the Evolution,” Journal of the Academy of Marketing Science (36:1), pp. 1-10.

Wolff, E. 2002. "Productivity, Computerization and Skill Change," Federal Reserve Bank of Atlanta Economic Review, pp. 63-78.

\section{About the Panelists}

Neil Ramiller is the Ahlbrandt Professor in the Management of Innovation and Technology at Portland State University's School of Business Administration. His primary research activities address the management of information technology innovations, with a particular focus on the role that rhetoric, narrative, and discourse play in shaping innovation processes and negotiating multiparty interests within organizations and across interorganizational fields. He also conducts work on the social construction of information technology scholarship, and the implementation of the "linguistic turn" in information technology studies. Neil has presented his work at a variety of national and international conferences, and published articles in a number of journals, including Journal of the Association for Information Systems, MIS Quarterly, Information and Organization, Information Technology \& People, Organization Science, Journal of Management Information Systems, and Information Systems Research. Neil can be reached at neilr@sba.pdx.edu.

Elizabeth Davidson is the W. Ruel Johnson Distinguished Professor of Information Technology Management and Department Chair at the Shidler College of Business, University of Hawaii at Manoa. In her research, she has examined social structure change associated with computerized physician order entry in hospitals and barriers to adoption of electronic medical records by small physician practices. Elizabeth currently serves as research director for an action research program attempting to build a community of practice around implementation of health information technology and its use to improve patient outcomes among small practices in Hawaii. She also serves as an associate editor for European Journal of Information Systems and MIS Quarterly and on the editorial boards of Information and Organizations and Information Technology \& People. Elizabeth can be reached at edavidso@hawaii.edu.

Erica Wagner is an assistant professor of Information Systems at Cornell University's School of Hotel Administration. She earned her Ph.D. from the London School of Economics and has an undergraduate degree in accounting. Her research interests focus on the ways software is "made to work" within different organizational contexts. The implication of this focus is theoretical development related to how technology is accepted within organizations, even when it is initially seen as problematic. Her research has been published in a variety of outlets including Information and Organization, Journal of the Association for Information Systems, Communi- 
cations of the ACM, and the Journal of Strategic Information Systems. Erica can be reached at elw32@cornell.edu.

Steve Sawyer is a founding member and an associate professor at the Pennsylvania State University's College of Information Sciences and Technology. Steve holds affiliate appointments in the Department of Management and Organization; the Department of Labor Studies and Employer Relations; and the program in Science, Technology and Society. Steve does social and organizational informatics research with a particular focus on people working together using information and communication technologies. Steve can be reached at sawyer@ist.psu.edu. 